\title{
Biosimilars: The New Era of Drug Development?
}

\section{Keane O Soluade and Duc P Do*}

Department of Pharmaceutical Sciences, College of Pharmacy, Chicago State University, Chicago, IL, USA

\section{Introduction}

The biopharmaceutical industry has come a long way since the United States Food and Drug Administration (FDA) approval of the first biopharmaceutical (biologic) product insulin in 1982 [1]. In 2012, five of the top ten selling prescription drugs were biopharmaceuticals [2]. Biopharmaceutical products have provided novel treatment modalities for life-threatening and rare diseases. In recent years, pharmaceutical companies are ramping up on their development of biosimilars because many patents on biological products are expiring and this enables them to earn profits from the biopharmaceutical market [3]. Biosimilars are expected to offer competition to some of the most expensive drugs on the pharmaceutical market. Biosimilars are defined as a highly similar form of innovator's biological products and are produced after the patent protections of such innovator biological products have expired [4-7]. Biosimilars are also known as follow-on biologicals, similar biologics, and similar biotherapeutic product or subsequent-entry biologics.

Biopharmaceutical products are composed of large and complex molecules developed using varied cell lines, unique manufacturing and purification processes, which would make it impossible to create an exact copy [8]. According to the US FDA, small-molecule drugs are the only drugs that can be referred to as true "generics" [5]. Unlike small-molecule drugs which are produced through chemical processes, biologics are made using living cells derived from human or animal sources. Biopharmaceuticals may also be produced synthetically using biotechnology. A biological product is composed of significantly larger and more complex molecules than small-molecule drugs [4,5]. A small difference in the cell line used in developing a biosimilar or in the manufacturing process or approach developed for such a biosimilar can result in quantifiable changes from its referenced product $[8,9]$. In addition, a biosimilar must be very similar to its approved reference biological product and must not have any clinically significant differences from the reference product in relation to safety, purity and efficacy $[5,6]$. Another major challenge to biosimilar drug development is determining which component of the biopharmaceutical is the active ingredient. In biopharmaceuticals, the clinical efficacy may be a result of the synergistic effects of more than one component and this factor may limit the ability to demonstrate similarity [10].

\section{Biosimilar Drug Development}

The process of developing a biosimilar can be a very challenging and meticulous task. To determine similarity with an originator referenced product, comprehensive physiochemical and biological characterization studies must be performed [11]. A reproducible manufacturing process must be established for developing the biosimilar using "good manufacturing practices." Bioequivalence of the biosimilar and innovator products must also be acquired by conducting extensive preclinical and clinical trials $[4,9]$.

Although the biosimilar development in the United States is in its infancy, the FDA has issued draft guidances to the industry. These draft guidances are to assist in the development and approval of biosimilars in the United States $[9,12,13]$. The FDA suggested that sponsors use a stepwise approach in determining the similarity between a biosimilar and the referenced innovator product. This stepwise approach should consist of analyzing the similarities of the proposed biosimilar and its reference product in regards to structure, function, animal toxicity, pharmacokinetic $(\mathrm{PK})$ and pharmacodynamic $(\mathrm{PD})$ properties as well as their chemical safety, purity and efficacy profiles [12,13]. According to the FDA draft guidances, the complexity in the nature and structure of biopharmaceuticals, using data from foreign approved products in demonstrating similarity and post marketing studies to be conducted are also factors to consider [12]. A totality-of-the-evidence submitted to the FDA in proving biosimilarity will also be considered when reviewing applications for biosimilars. The totality-of-the-evidence approach suggests that the FDA will be basing their regulatory decisions on the vast majority of evidence submitted by sponsors $[9,14]$. The draft guidances are only recommendations and not required for those choosing to demonstrate biosimilarity using an alternate approach as long as the strategy does not violate currently applicable regulations and statutes [13].

\section{United States Biosimilar Regulatory Considerations}

From a global perspective of approving biosimilars, the US FDA lags behind other regulatory authorities [14]. Globally, the European Medicines Agency (EMA) Committee for Medicinal Products for $\mathrm{Hu}$ man Use (CHMP) was a forerunner to establish a regulatory pathway for approving biosimilars. To date, 14 biosimilars (not counting monoclonal antibody biosimilars) have been approved by the EMA $[6,15]$. In the United States, biological originators are granted a 12-year exclusivity period to encourage research and development of newer biologics and allow recovery of research and development costs. Under this exclusivity, no application for a biosimilar may be 'submitted' to the FDA until 4 years after the reference product has been licensed and no biosimilar application can be 'approved' until 12 years after the reference product has been licensed [14].

The Patient Protection and Affordable Care Act of 2010 (ACA) actualized the future for approving biosimilars in the U.S through its subtitle, the Biologics Price Competition and Innovation Act of 2009 (BCPIA). The BCPIA enabled the amendment of the Public Health Service Act (PHSA), which licenses biopharmaceuticals, unlike traditional drugs which are licensed under the Food, Drug and Cosmetic Act (FDCA). The BCPIA allowed the creation of an abbreviated approval pathway for products that are "biosimilar" to already licensed biological products that are currently on the U.S market $[5,9,12]$. Recently, the

*Corresponding author: Duc P Do, 9501 S King Drive, Douglas Hall 206, Chicago, IL 60628, USA, Tel: 773-821-2597; Fax: 773-821-2595; E-mail: ddo@csu.edu

Received August 12, 2013; Accepted August 17, 2013; Published August 25 2013

Citation: Soluade KO, Do DP (2013) Biosimilars: The New Era of Drug Development? J Bioequiv Availab 5: e40. doi:10.4172/jbb.10000e40

Copyright: (c) 2013 Soluade KO, et al. This is an open-access article distributed under the terms of the Creative Commons Attribution License, which permits unrestricted use, distribution, and reproduction in any medium, provided the original author and source are credited. 
Biosimilar User Fee Act of 2012 (BsUFA) was passed and gave the FDA the authorization to assess and collect fees for providing the necessary resources to process and evaluate biosimilar applications $[14,16]$.

\section{Conclusion}

Biosimilar drugs are currently a major issue of discussion in the pharmaceutical and healthcare industry. Patent expirations of top selling biopharmaceuticals and economic competition for cheaper drug products have opened avenues for the development of biosimilars. Despite challenges in developing biosimilars, several major pharmaceutical companies have sought regulatory approvals. To date, 14 biosimilars (not counting monoclonal antibody biosimilars) have been approved by the EMA $[6,15]$. Recently, in June 2013, the EMA approved the first two monoclonal antibody biosimilars for autoimmune diseases $[17,18]$. This approval is a major breakthrough for the biopharmaceutical industry. In July 2013, Eli Lilly and Boehringer Ingelheim announced that their biosimilar long acting insulin product, LY2963016, was accepted for review by the EMA for type I and II diabetes [19]. An increase in biosimilars will also prove to be beneficial as it will significantly reduce cost to patients and allow for greater patient accessibility to quality healthcare [9]. However, as biosimilar products are developed, it is important that they meet quality, safety, and efficacy standards to achieve therapeutic outcomes in patients. Additionally, the development of sensitive in vitro characterization and analytical methods to establish similarity between the innovator's drug product and the biosimilar is highly desired.

\section{References}

1. Junod SW (2007) Celebrating a milestone: FDA's approval of first geneticallyengineered product. U. S. Food and Drug Administration.

2. Lindsley CW (2013) The top prescription drugs of 2012 globally: biologics dominate, but small molecule CNS drugs hold on to top spots. ACS Chem Neurosci 4: $905-907$.

3. Ahmed I, Kaspar B, Sharma U (2012) Biosimilars: impact of biologic product life cycle and European experience on the regulatory trajectory in the United States. Clin Ther 34: 400-419.
4. Kanase SJ, Gavhane YN, Khandekar A, Gurav AS, Yadav AV (2013) Biosimilar: an overview. IJPSR 4: 2132-2144.

5. (2010) Information for consumers (biosimilars). U.S. Food and Drug Administration.

6. (2013) Biosimilar medicines. European Medicines Agency.

7. Gecse KB, Khanna R, van den Brink GR, Ponsioen CY, Lowenberg M, et al (2013) Biosimilars in IBD: hope or expectation? Gut 62: 803-807.

8. Nowicki M (2007) Basic facts about biosimilars. Kidney Blood Press Res 30 267-272.

9. Waller CF (2012) Biosimilars and their use in hematology and oncology. Community Oncology 9: 198-205.

10. Abood, RR (2013) Pharmacy practice and the law (7th edition), Burlington, MA Jones \& Bartlett Learning.

11. Jeske W, Walenga JM, Hoppensteadt D, Fareed J (2013) Update on the safety and bioequivalence of biosimilars - focus on enoxaparin. Drug Healthc Patient Saf 5: 133-141.

12. (2010) Information for industry (Biosimilars). U.S. Food and Drug Administration.

13. (2012) Scientific considerations in demonstrating biosimilarity to a reference product. Guidance for industry. U.S. Department of Health and Human Services Food and Drug Administration.

14. Bourgoin AF, Nuskey B (2013) White paper: an outlook on U.S. biosimilar competition. Drugs Today (Barc) 49: 399-410.

15. Sekhon BS, Saluja V (2011) Biosimilars: an overview. Biosimilars 2011: 1-11.

16. (2013) Biosimilar user fee act (BsUFA). U.S. Food and Drug Administration.

17. (2013) EMA backs approval of first biosimilar monoclonal antibodies. Nat Rev Drug Discov 12: 568.

18. Beck A, Reichert JM (2013) Approval of the first biosimilar antibodies in Europe: A major landmark for the biopharmaceutical industry. MAbs 5.

19. Hull T, Warsinsky R (2013) European medicines agency accepted companies marketing authorisation application. Eli Lilly and Company and Boehringer Ingelheim announce regulatory submission for new insulin glargine biosimilar product, Germany. 